\title{
O Espaço Ciência Interativa e a educação não formal: considerações sobre a relação escola-comunidade e a formação escolar
}

\section{The Interactive Science Space and non-formal education: considerations on the school-community relationship and school training}

\author{
${ }^{1}$ Cristiane Aparecida Fernandes de Jesus cristianeferness@gmail.com \\ ${ }^{1}$ Cleuber Fabiano Pereira Mendes \\ ${ }^{1}$ Jorge Cardoso Messeder
}

\section{RESUMO}

O presente artigo traz uma análise comparativa em relação à concepção de educação formal de professores de física, química e biologia, do ensino médio, e educação não formal. Além disso, é apresentada uma investigação sobre a importância da educação não formal para o desenvolvimento do discente em formação. A pesquisa foi realizada no Espaço Ciência Interativa em Mesquita, na Baixada Fluminense (RJ), e em uma escola da rede pública estadual situada no mesmo município. O objetivo principal foi averiguar a percepção de alguns professores sobre o ensino de ciências em espaços não formais e como ocorre a relação entre a escola e o espaço de ciências, locais da pesquisa. Para tanto, foram aplicados questionários com questões abertas acerca da temática, sendo avaliados através da Análise Textual Discursiva (ATD). A investigação indicou, que apesar da proximidade entre os locais da pesquisa, a relação escola-comunidade existente era falha, e que não havia diálogos entre as duas comunidades educativas. Portanto, pode-se compreender como a educação formal e não formal são percebidas como modalidades de educação, e a importância de estarem correlacionadas na formação do indivíduo enquanto cidadão ativo.

Palavras-chave: Educação não formal. Relação escola-comunidade. Espaço Ciência Interativa.

\begin{abstract}
The present article brings a comparative analysis in relation to the conception of formal and not formal education of physics, chemistry and biology teachers of the high school. Moreover, an inquiry on the importance of not formal education is presented for the development of the learner. The research in the Interactive Science Space, in Mesquita, in the Baixada Fluminense (Rio de Janeiro/Brazil), was carried and in a public state school in the same town. Had as objectives to check the perception of someone teachers about the learn sciences not formal spaces and as occur the relation between the school and the sciences space, places of the research. Therefore, being evaluated questionnaires with open questions concerning the thematic were applied through "Discursive Textual Analysis" (DTA). The results indicated that in spice off the proximity among the places of the research, the school-community existing relation was imperfect, and that did not have dialogues between the two educative communities. Moreover, it can be understood as the formal education and the not formal one is perceived as education modalities, and the importance to be correlated in the formation of the individual while active citizen.
\end{abstract}

Keywords: No-formal education. School community relationship. Interactive Science Space.

1 Instituto Federal de Educação, Ciência e Tecnologia do Rio de Janeiro (IFRJ) 


\section{INTRODUÇÃO}

Hodiernamente a sociedade necessita de indivíduos pensantes e críticos que possam colaborar de forma ativa diante de um novo paradigma imposto ao longo dos anos. Esse padrão busca cidadãos que estejam inseridos nas demandas de um país globalizado. Diante disso, torna-se indispensável um olhar minucioso em relação a fatores que podem colaborar com a formação desse sujeito. A Lei de Diretrizes e Bases da Educação Nacional, em seu artigo $1^{\circ}$, declara que "os processos formativos que se desenvolvem na vida familiar, na convivência humana, no trabalho, nas instituições de ensino e pesquisa, nos movimentos sociais e organizações da sociedade civil e nas manifestações culturais.” (BRASIL, 1996).

A partir da proposta exposta anteriormente, observa-se que a educação vai bem além dos muros da escola, porém, essa responsabilidade recai, algumas vezes, sobre organização escolar. Sobre isso Moura e Zucchetti afirmam que:

(...) é preciso considerar que as práticas de educação que ocorrem além da escola (em especial nos projetos socioeducativos e nos projetos que resultam de políticas públicas), ainda que contando com a presença de um mediador estagiário ou voluntário - o “educador” - em substituição à figura tradicional do professor, necessariamente visam implementar processos de ensino e aprendizagem. (MOURA; ZUCCHETTI, 2010, p. 632)

Dentro desse contexto, muitos autores destacam a existência de outras modalidades de educação que coexistem, são fundamentais e completam-se entre si. As citadas aqui são formais, não formais e informais, que estão associadas e não extinguem as demais modalidades.

Gadotti (2005, p.2), por exemplo, destaca que

A educação formal tem objetivos claros e específicos e é representada principalmente pelas escolas e universidades. Ela depende de uma diretriz educacional centralizada como o currículo, com estruturas hierárquicas e burocráticas, determinadas em nível nacional, com órgãos fiscalizadores dos ministérios da educação.

Em contrapartida, a educação não formal é mais difusa, menos hierárquica e menos burocrática. Os programas de educação não formal não precisam necessariamente seguir um sistema seqüencial e hierárquico de “progressão”. Podem ter duração variável, e podem, ou não, conceder certificados de aprendizagem.

Outros autores acreditam estar interligadas, pois se completam como declaram Bianconi e Vieira:

Enquanto a educação formal é aquela a qual todo cidadão tem direito garantido pelo estado e ocorre em instituições formais de ensino a educação informal ocorre "ao acaso" decorrente de processos espontâneos, ou seja, é aquela adquirida pelos pais, do convívio com amigos ou até mesmo de leituras [...]. Não há como sistematizar esse tipo de educação, pois depende de fatores inerentes da vida de cada cidadão e de suas experiências pessoais. Por outro lado, a chamada educação não formal tem características de ambos formais e informal, pois é sistemática e organizada, mas ocorre fora do ambiente formal de ensino. (BIANCONNI; VIEIRA 2007, p.22).

Fávero, (2007, p.614) expõe sobre esses termos, indicando que o não formal tem sido uma categoria utilizada com bastante frequiência na área de educação para situar atividades e experiências diversas, distintas das atividades e experiências que ocorrem nas escolas, por sua vez classificadas como formais e muitas vezes a elas referidas. Na verdade, desde há muito tempo classificava-se como extra-escolares atividades que ocorriam à margem das escolas, mas que reforçavam a aprendizagem escolar, nas bibliotecas, no cinema, no esporte, na arte. 
Os conceitos sobre educação formal se aproximam e destacam a formalidade, porém a educação não formal destoa em alguns pontos, mas a maior variável seriam as definições do espaço em que tais educações ocorrem. Jacobucci (2008, p.57), depois de uma vasta explanação, define superficialmente o que seria a diferença entre espaços formais e não formais de educação: “de forma sintética, pode-se dizer que os espaços formais de Educação se referem a Instituições Educacionais, enquanto que os espaços não-formais se relacionam com Instituições cuja função básica não é a Educação formal e com lugares não-institucionalizados. ”

Porém, para Gohn (2008) e Gadotti (2005), a educação não formal vai muito além de espaços determinados de educação, sendo múltiplos, como bairro, associações, organização que estruturam e coordenam os movimentos sociais, nas igrejas e sindicatos e nos partidos políticos, nas Organizações Não-Governamentais (ONG), nos espaços culturais e nas próprias escolas em seus espaços interativos com a comunidade educativa.

Nesse trabalho foi adotado o conceito acima citado como norteador, pois se compreende que qualquer espaço pode ser utilizado, desde que intencionalmente, para a educação não formal.

Entende-se que a relação escola-comunidade é um fator importante para que os alunos percebam sua participação nas decisões de uma civilização. Sendo assim, a escolha dos locais ocorreu devido à existência de um espaço não formal localizado a poucos metros de uma escola caracterizada como espaço formal, conforme as definições apresentadas.

O local escolhido foi o Espaço Ciência Interativa (ECI) que é financiado pelo Governo Federal, e se localiza no Instituto Federal do Rio de Janeiro campus Mesquita, na Baixada Fluminense (RJ). O ECI apresenta oficinas de Ciências e recebe escolas e públicos de diferentes níveis de escolaridade. No espaço acontecem visitas mediadas, cursos de pós-graduação em educação e divulgação científica, além de cursos de formação de professores do ensino básico e formação de mediadores.

Na escola escolhida para a pesquisa a maior parte dos alunos é do bairro Mesquita e adjacências, e a opção por essa escola se dá pelo fato de que a interação entre o ECI e a mesma seria uma relação social definida como “escola-comunidade”, visto que as duas instituições estão no mesmo território. Gohn (2004, p.51) apresenta que "estamos plenamente de acordo com a busca de integração da escola com a comunidade localizada no território de seu entorno, que denominamos 'comunidade educativa' propriamente dita. [...] a articulação escola-comunidade é uma ação necessária e urgente.”

Perante as condições, objetivou-se nesse trabalho perceber como os professores dos dois espaços entendem a educação não formal e qual seria o papel dessa modalidade na perspectiva dos mesmos para a formação dos alunos da escola, assim como apreender a possível existência de uma relação anteriormente estabelecida entre as unidades.

\section{METODOLOGIA}

Tendo a pesquisa característica expositiva, utilizou-se um questionário como instrumento para agrupar os dados, com questões pré-elaboradas, dispostas sequencialmente em itens que constituem o tema da pesquisa, com o objetivo de obter opiniões e entendimentos sobre o assunto abordado. As análises dos questionários foram qualitativas, no intuito de ter respostas mais detalhadas e enriquecedoras com a utilização do método de Análise Textual Discursiva (ATD) (MORAES; GALIAZZI, 2007).

O questionário (Quadro 1) apresenta oito perguntas abertas para que os professores participantes ficassem livres para responder, de modo que fosse possível obter informações variadas e com riqueza de detalhes. 


\section{Quadro 1 - Questões utilizadas no questionário.}

1- Há quantos anos você exerce a docência?

2- O que é educação formal e educação não formal no seu ponto de vista? Há diferenças? Quais?

3- A educação não formal influenciou de alguma maneira para sua formação? Caso a resposta seja sim, como?

4- Você acha que a educação não formal contribui para a formação do aluno como cidadão? Caso a resposta seja sim, como contribui? Caso a resposta seja não, por que não contribui?

5- A educação não formal pode ser utilizada como um meio facilitador pelos professores? Como?

6- Como trabalhar para que esses alunos tenham mais interesse em conhecer os espaços de divulgação científica?

7- Em sua opinião qual a importância de um espaço de divulgação cientifica em Mesquita?

8- Quais são os benefícios que o Espaço Ciência Interativa (ECI) pode levar aos alunos desta região, em especial aos alunos dessa escola?

Fonte: dos autores.

A estratégia de entregar em mãos os questionários possibilitou uma resposta rápida dos participantes. A pesquisa contou com vinte respondentes, porém, foram escolhidas, para esse artigo, as análises de oito respostas. O critério de escolha dessas respostas foi atribuído de acordo com as unidades teóricas, que serão explicadas posteriormente, pois algumas destoavam da ideia central da questão. logo, as escolhidas foram as mais marcantes sobre o tema, visto que, na ATD buscam-se respostas significativas e que contribuam para um entendimento mais aprofundado da temática pesquisada.

Com relação aos sujeitos da pesquisa, participaram profissionais que atuam nos campos da divulgação científica e educação não formal, e também professores do ensino médio, mais especificamente professores de biologia, física e química.

Para análise dos questionários foi utilizado o método qualitativo de ATD, que de acordo com Moraes e Galiazzi (2007, p. 14) "propõe descrever e interpretar alguns dos sentidos que a leitura de um conjunto de textos pode suscitar”.

A ATD, a Análise do Conteúdo (AC) e a Análise do Discurso (AD) são metodologias que compõe um domínio único e que apresentam semelhanças e diferenças entre si. Moraes e Galiazzi (op. cit.) destacam que este método se enquadra entre extremos da AC e da AD. Além disso, cada uma das abordagens tem seu espaço dentro da pesquisa qualitativa e, apesar das divergências, não se excluem (p.160) .

A ATD se divide em três etapas distintas e importantes denominadas unitarização, categorização e produção de metatextos, que serão explicitadas sucintamente a seguir:

- Desmontagem dos textos ou unitarização: é a primeira etapa que, segundo Moraes e Galiazzi (2007), "implica examinar os textos em seus detalhes, fragmentando-os no sentido de atingir unidades constituintes, enunciados referentes aos fenômenos estudados” (p. 11); é importante, apesar da fragmentação, não perder o vínculo com a parte do texto de que foi retirado. Para isso cada unidade receberá um título, que trará a ideia principal do trecho e um código, mantendo essa conexão. O pesquisador decidirá como serão fragmentados seus textos, e cada parte da desconstrução (dos textos) vai formar uma unidade de significado ou sentido (p. 18). Tais unidades podem receber classificação de acordo 
com a sua finalidade, sendo empíricas quando coletadas para a pesquisa, ou teóricas, se provenientes dos autores utilizados para embasar o tema pesquisado;

- Estabelecimento de relações ou categorização: é a segunda etapa e consiste na formação de categorias, quando, de acordo com a semelhança das unidades posteriormente elaboradas, são gerados conjuntos, sejam elas empíricas ou teóricas.

- Comunicação ou produção de metatextos: essa última etapa compreende uma visão holística do processo. O objetivo é elaborar um texto descritivo e interpretativo, denominado metatexto, que surgirá a partir das categorias antes definidas.

Desse modo, a ATD pode ser compreendida "como um processo auto-organizado de construção de novos significados em relação a determinado objetos de estudo, a partir de materiais textuais referentes a esses fenômenos.” (p. 45).

A pesquisa qualitativa em ensino utiliza-se desta metodologia porque trabalha com o que pensam os alunos ou professores. Busca-se entender o significado de suas ações, suas falas; sendo assim, para a pesquisa quantitativa não teria validade, pois as respostas objetivas têm caráter impessoal e não permitem a atribuição de significados, e sim de dados.

A análise dos dados foi feita de forma minuciosa, de modo que permitiu um resultado promissor. A realização das etapas ocorreu da seguinte forma:

- Foram escolhidos códigos para identificar as unidades montadas e suas relações com a unidade teórica. Todas as respostas foram associadas a uma unidade. Com exceção das primeiras, que se julgou não terem relação com as demais, de uma maneira geral. ${ }^{2}$

- Foram formuladas unidades teóricas e empíricas de acordo com as unidades obtidas através das respostas dos professores e embasamento teórico. Quatro unidades foram desenvolvidas: Unidade Teórica A - Conceito de educação não formal e formal; Unidade Teórica B - Influências da educação não formal na formação do discente; Unidade Teórica C - Relação Escola - Comunidade; Unidade Teórica D - A importância de um espaço não formal em Mesquita.

- A partir das unidades, foram criadas três categorias:

- Concepções e influências da educação não formal;

- Percepções sobre a relação escola-comunidade;

- A importância de um espaço não formal em Mesquita.

- Os metatextos foram produzidos com bases nas categorias delimitadas.

Para entendimento do texto, os códigos foram atribuídos da seguinte maneira, segue um modelo no Quadro 2:

2 Inicialmente a intenção da questão 1 era perceber se havia a relação das concepções com os anos de docência, porém o quantitativo de respostas não foi suficiente para essa conclusão. 
Quadro 2 - Códigos de unidades empíricas e teóricas.

\begin{tabular}{|c|}
\hline E2P1Q1UT - Espaço 2 - ambiente formal; P1 - professor 1 - Q1 \\
- Questão 1 - UA - Unidade Teórica (A, B, C, D) \\
\hline E1P1Q1UT - Espaço 1 - ambiente não formal; P1 - professor 1 - \\
Q1 - Questão 1 - UB - Unidade Teórica (A.B, C, D) \\
\hline
\end{tabular}

Fonte: dos autores.

\section{$3 \quad$ RESULTADOS E DISCUSSÕES}

Os resultados foram agrupados em dois metatextos produzidos a partir das respostas dos professores, sendo utilizadas muitas das concepções desses para consolidar os objetivos dos textos finais a fim de demonstrar de forma mais completa a percepção dos mesmos, utilizando também embasamento teórico para fundamentá-las. É importante ressaltar que as respostas obtidas dos profissionais foram mantidas com a grafia e concordância originais, para que não houvesse alteração do texto.

\section{1 Metatexto 1 - Concepções e influências da educação não formal.}

O objetivo das perguntas direcionadas nesse texto foi perceber qual o entendimento dos docentes sobre o tema e as influências que tiveram em sua formação, assim como a que poderia ser apreendida pelos discentes em formação.

Sobre educação formal e não formal, em sua maioria os participantes demonstraram conhecimento sobre o tema, independente do espaço em que lecionavam, como pode ser observado a seguir:

E2P1Q2UA: “Educação formal é o ensino dado por um profissional dentro de uma instituição regularizada pelo MEC. (Colégio estaduais, particulares ...). Educação não formal é o ensino dado fora de uma instituição regularizada pelo MEC (professor particular, pré-vestibular em igreja...) "

E2P2Q2UA: "Educação formal é aquela que acontece na escola mediante a participação do professor. Educação não formal é aquela que ocorre através da interação com o cotidiano no nosso mundo."

E1P1Q2UA: "Educação formal é aquela em que o aluno recebe uma certificação ao termino do curso. A não formal não tem uma preocupação em certificar.”

E2P4Q2UA: "Educação formal é aquela praticada em salas de aula, com livros, professores etc. Já a educação não formal é realizada em espaços científicos, museus, bibliotecas, salas de cinema etc."

Pode-se perceber que diversos entendimentos condizem com o que foi referenciado anteriormente sobre os conceitos de educação formal e não formal.

Alguns atribuem uma dimensão maior, demonstrando a dificuldade em propor limites nas categorias. Há também confusão entre os conceitos de não formal e informal.

E2P3Q2UA: “Formal seria o acadêmico. Já o informal seria a ética e moral.” 
Muitas visões convergiam e divergiam, levando a se concluir; a partir das respostas, como foi importante a educação formal e, em alguns casos, até mesmo o direcionamento da carreira com base no que aconteceu durante a formação docente. Isso demonstra quão decisivo pode ser o contato com outras modalidades.

E1P1Q3UB: "Fui estagiário em uma empresa que era contratada por escolas p/ fazer experiências e levar bichos nas aulas de ciências (apesar de ser uma escola, considero esse trabalho como não formal, pois, como empresa, não tínhamos o compromisso em formar alunos). Além disso fui mediador em um museu de ciência."

E1P2Q3UB: "Durante minha graduação atuei como mediadora em um museu de ciências, de modo que diante da minha inserção nesse espaço de educação não formal, iniciei meu primeiro projeto de pesquisa científica no museu em questão.”

E1P4Q3UB: "Durante a minha graduação, tive a oportunidade de participar de projeto de pesquisa sobre espaços de educação não formal. Adicionalmente, também atuei como mediadora de um centro de ciências, influenciando muito minha formação. Como resultado dessa contribuição, informo que a educação não formal pertence à temática que desenvolvi durante meu mestrado.”

E1P3Q3UB: "Sim. Foi durante a minha participação como bolsista de iniciação cientifica no Museu de Astronomia e Ciências Afins (MAST) ao final da minha graduação, que me despertou o interesse para a área da educação não formal e para o seu dialogo com os espaços de educação não formal."

E2P1Q3U2B: "Dei muitas aulas particulares para colegas, parentes de conhecidos, vizinhos para dá o ponto de decisão da escolha de profissão."

Os professores também destacaram a influência que poderá ser gerada na vida dos alunos em decorrência do contato com essa modalidade de educação.

E2P1Q8UB: "Conhecer que a ciência faz/tem muitas pesquisas que beneficia a humanidade, basta o interesse do individuo na dedicação da pesquisa. Então, no meio de tantos alunos, através dessas visitações podemos estimular a um aluno a fazer parte do meio de pesquisa da ciência. "

E2P2Q4UB: “Sim, a formação plena do cidadão passa pela educação formal, não formal e informal.”

E2P3Q7UB: "Favorece ao conhecimento, portanto, o crescimento acadêmico "anda junto" com o pessoal (cidadania).”

E2P3Q7UB: “Ao conhecimento, ao incentivo ao crescimento acadêmico e junto ao pessoal (ética e moral) contribuindo para a cidadania do indivíduo.”

E2P4Q4UB: "Sim, pois vivenciando teorias em ambientes voltados à ciência o aluno pode desenvolver melhor o seu senso crítico e aguçar sua curiosidade."

E1P4Q4UB: "Contribui na medida em que favorece a aproximação deste individuo às questões relacionadas a sua formação que possivelmente não foram abordadas no ambiente escolar.”

Gohn (2004, p. 54) afirma existirem diversos tipos de aprendizagem a partir da educação não formal, dentre eles a cultural, que se refere aos quais elementos que constroem a identidade de um grupo, suas diferenças, diversidades e adversidades, e também a social, que está relacionada a "como falar e ouvir em público, hábitos e comportamentos de grupos e pessoas, como se portar diante do outro, como se comportar em espaços diferenciados”, e à ética, que é construída "a partir da vivência ou observação do outro, centrada em valores como 
bem comum, solidariedade, compartilhamento. Esses valores são fundamentais para a construção de um campo ético-político."

Com as respostas dos professores pode-se confirmar o que Moura e Zucchetti (2010) afirmam:

[...] na educação desenvolvida na escola, não existem os processos de compartilhamento de experiências, principalmente, em espaços e ações coletivas cotidianas. Na escola, a despeito da sua explícita intenção de ensinar apenas os valores próprios da cultura hegemônica (erudita), também circulam os valores de outras culturas de pertencimento, herdados pela tradição oral e, principalmente, sentimentos, emoções e paixões. Somente nessa perspectiva, tendemos a concordar que educação desenvolvida nas escolas ocorre fora do “mundo da vida” (MOURA e ZUCCHETTI, 2010, p. 636).

Dentro das respostas analisadas, percebe-se a importância do ensino não formal para a formação dos discentes nas concepções dos professores, que destacam a utilização de associações em sala para corroborar o processo como um todo.

E1P2Q5UB: "O professor deve se apropriar da educação não formal, sobretudo quando se analisa as atividades oferecidas pelos centros culturais, jardins botânicos os centros e museus de ciência. Todos esses espaços têm como proposta trazer contribuições para a educação formal, uma vez que desenvolvem ações específicas para o público escolar. Sendo assim, tais espaços são potencialmente coadjuvantes no processo de ensino/aprendizagem."

E1P4Q5UB: “[...] possibilita ao professor abordar questões e assuntos da sua matéria (ou correlata) num ambiente diferenciado, além da não obrigatoriedade de seguir um roteiro fechado, como na aula formal."

Depreende-se aqui que os docentes consideram importante outras modalidades conjuntas com a educação escolar para a formação dos discentes.

\section{2 Metatexto 2 - Percepções sobre a relação escola-comunidade, considerando a importância da exis- tência de um espaço não formal em Mesquita.}

O discurso aqui é motivado pelo estreitamento da relação escola comunidade que, como citado anteriormente, se faz urgente.

Sobre isso os professores mostraram-se favoráveis e consideraram viável o estreitamento das relações e a existência de um espaço que possa facilitar o acesso a outras categorias de educação.

\footnotetext{
"Quando se fala em abertura das escolas para a comunidade, deve-se lembrar dos pais como atores por excelência. Em raros casos, pensa-se em outras instituições, organizações ou associações, do próprio bairro ou da região onde a escola está situada, que fazem articulações com a escola, como os sindicatos e as associações de docentes” (MOURA e ZUCCHETTI 2010, p. 41).
}

Apesar de estarem próximos, foi notável que mesmo considerando importante a relação, os espaços não tinham um relacionamento prévio estabelecido. Além disso, alguns professores não conheciam o ECI. Da mesma forma, os professores do espaço formal acharam necessária uma melhora na divulgação. Um deles até propôs a existência de um convênio entre as partes. Sobre isso foram encontradas respostas nas seguintes perspectivas:

E1P4Q8UC: "São inúmeros e inimagináveis, tendo em vista que não conheço a realidade interna do colégio e, assim, excluir algum benefício de uma suposta lista. Apenas para citar alguns, posso apontar a proximidade do local, de fácil acesso; a possível parceria com os alunos para o desenvolvimento de projetos entre o espaço e a escola; a apropriação dos estudantes por um espaço científico; entre muitos outros.” 
E1P2Q8UC: "O ECI deve estreitar a relação com a escola em questão, uma vez que os docentes poderiam se apropriar e utilizar o espaço como coadjuvante no processo de ensino e aprendizagem em ciências. "

E2P2Q6UB: "O primeiro passo é uma melhor divulgação destes espaços, conhecendo os horários de funcionamento, acervo etc. fica facilitado aos professores divulgarem e incentivar a visitação individual ou em grupos/turmas a esses espaços, fazendo disto um belo programa cultural.”

E1P1Q8UC: “[...]. Quanto ao colégio acho que as possibilidades são muitas, uma vez que somos vizinhos. Porém, creio que deveriam haver esforços mútuos para fechar parcerias de modo que projetos fossem desenvolvidos por ambas as partes a fim de melhorar o ensino de ciências da escola e aumenta a freqüência do publico do entorno no ECI! ”

E2P2Q7UD: "A importância é enorme. Se as escolas municipais/estaduais/particulares estivessem integradas e cientes de seu acervo, seus horários, guias, programações especiais e regulares, com certeza haveria uma maior integração entre as escolas e o centro."

A existência de um espaço de educação não formal em Mesquita é encarada pelos professores como um passo importante para a localidade. Suas opiniões destacam questões sociais e culturais que são observadas em um local afastado dos Centros onde geralmente se encontram tais espaços.

E1P3Q6UB: "É necessário que esses espaços sejam apresentados aos estudantes de modo a inserir esses espaços em sua pratica cultural. A distribuição geográfica, cultural e social desses espaços favorece que eles estejam pouco (ou não estejam) disponíveis para grande parte da população.”

E2P4Q7UD: "Acho muito importante, pois o fato de estarmos afastados dos grandes centros de ciência e cultura no Rio de Janeiro deve funcionar como um grande aliado na educação dos jovens da localidade."

E1P1Q7UD: "Por ser uma região historicamente "abandonada" (não achei palavra melhor) pelos governos, o ensino acaba ficando enfraquecido também, o que reforça a idéia de que as matérias são chatas e a escola é ruim. Acho que um espaço desse em Mesquita pode ajudar as pessoas a se interessar por ciência. Também é importante para mostrar que a ciência não é coisa só de TV; que é possível que qualquer um se torne cientista. Que ciência faz parte do nosso dia-a-dia. Creio também que um espaço assim possa ajudar a aumentar a auto estima das pessoas, pois algo que antes só fazia parte da capital agora também está na baixada."

Muitos afirmam a carência e o abandono das autoridades para com a localidade. Assim percebe-se que:

\begin{abstract}
Neste novo século, os índices de violência e de conflitos sociais são extremamente altos, poucos recorrem à mediação do Estado em busca de soluções para seus problemas; ao contrário, o que se constata é um descrédito no Estado, a falência de várias estruturas de representação política e o enfraquecimento de algo similar a uma cultura cívica, aquela que preserva e desenvolve certos valores de pertencimento nos indivíduos e grupos sociais. (GOHN, 2004 p. 52).
\end{abstract}

Algumas considerações foram feitas em relação às alternativas que são possíveis para aproximar o grupo do ECI, como é possível observar:

E1P1Q6UB: "Mostrando a eles que isso existe. Grande parte dos alunos não vai a esses espaços por que nem sabem que eles existem. Alem disso o pensamento cultural de que ciências é chato, matemática é um saco e física e química é um porre, atrapalha bastante o interesse por esses espaços. ”

E1P2Q7UD: “A presença de um museu de ciência no município em questão representa a possibilidade de aproximar os moradores e estudantes da região do conhecimento científico. Sobretudo por se tratar de uma região carente de aparelhos culturais e científicos." 
E1P4Q7UD: "O município de Mesquita e toda a região da Baixada Fluminense carece de espaços de divulgação científica, considerando que esta região compreende cerca de 13 municípios e contem apenas 3 centros de ciências, ao todo. ”

Esse texto proporciona a visibilidade de uma ação emergente para a conjunção desses dois espaços em prol da educação.

\section{CONSIDERAÇÕES FINAIS}

A pesquisa realizada foi importante para que se percebam quão necessárias são as discussões sobre o ambiente escolar, sua relação com a comunidade e as possíveis agregações ao processo formativo do corpo discente envolvido.

Com os dados obtidos pode-se perceber como é importante a existência de um espaço não formal e a necessidade de aproximação de ambas as partes para que seja realizada uma movimentação em prol da educação. A educação não formal possibilita uma ampliação da percepção de mundo que o indivíduo tem e contribui de forma significativa para o desenvolvimento do aluno enquanto cidadão inserido em um grupo social.

Concernente às discussões levantadas, percebe-se que alguns fatores são importantes para estabelecer uma relação entre o corpo escolar e a comunidade em que está envolvida, dentre eles, a comunicação entre as partes. Os espaços averiguados são tão próximos, e, até então, não mantinham contato e poderiam estar colaborando para o crescimento do local. Acredita-se que alternativas de novas atitudes por parte do educador em processos não formais de ensino e aprendizagem possam contribuir para que seus alunos se tornem profissionais adequados para lidar com as mais variadas situações deparadas no cotidiano de cada indivíduo. 


\section{REFERÊNCIAS}

BRASIL. Lei de Diretrizes e Bases da Educação Nacional. Lei n 9394, 23 de dezembro de 1996. Diário Oficial (da) República Federativa do Brasil, Brasília, 1996.

FÁVERO, O. Educação não formal: contextos, percursos e sujeitos. Educ. Soc. Campinas, vol. 28, n. 99, p. 614-617, maio/ago, 2007.

GADOTTI, M. A questão da educação formal/não formal. Institut international des droits de l'enfant (ide). Droit à l'éducation: solution à tous les problèmes ou problème sans solution? Sion (Suisse), 18 au 22 October 2005.

GOHN, M. G. A educação não formal e a relação escola-comunidade. ECCOS - Rev. Cient. UNINOVE, São Paulo, v. 6, n. 2, p. 39-65, 2004.

GOHN, M. G. Educação não formal e cultura política: impactos sobre o associativismo do terceiro setor. 4.ed. São Paulo: Cortez, 2008.

JACOBUCCI, D. Contribuições dos espaços não-formais de educação para a formação da cultura científica. Em Extensão, Uberlândia, V. 7, 2008.

MORAES, R.; GALIAZZI, M. C. Análise textual discursiva. Ijuí: Unijuí, 2007.

MOURA, E. P. G. e ZUCCHETTI, D. T. Educação além da Escola: acolhida a outros saberes. Cadernos de Pesquisa, v.40, n.140, p. 629-648, maio/ago. 2010.

VIEIRA, V. BIANCONI M. L. A importância do museu nacional da universidade federal do Rio de Janeiro para o ensino não formal em ciências. Ciências \& Cognição. Vol. 11: 21-36, 2007. 